\title{
A crise cambial e financeira da Turquia em 2001 e a sua recuperação econômica
}

\author{
Luciano Ferreira Gabriel* \\ José Luís Oreiro**
}

Uma severa crise cambial e bancária atingiu a Turquia em 2001 causando o colapso de um programa de estabilização após 14 meses de sua implantação. O regime cambial do tipo crawling peg foi abandonado e o câmbio flexível foi adotado em 22 de fevereiro de $2001^{54}$. A desvalorização cambial em relação ao dólar e ao euro chegou a atingir 33\% e quase $66 \%$, respectivamente.

Como podemos observar na tabela 1, na última década ocorreram graves crises cambiais e financeiras nas economias em desenvolvimento cujas repercussões se prolongaram, em maior ou menor grau, para as demais economias em desenvolvimento por meio do "efeito contágio".

Tabela 1. Crises cambiais e financeira

\begin{tabular}{lll}
\hline País & Mês & Ano \\
\hline México & Dezembro & 1994 \\
Tailândia & Julho & 1997 \\
Filipinas & Julho & 1997 \\
Indonésia & Agosto & 1997 \\
Malásia & Agosto & 1997 \\
Coréia & Novembro & 1997 \\
Rússia & Setembro & 1998 \\
Brasil & Janeiro & 1999 \\
Turquia & Fevereiro & 2001 \\
Argentina & Dezembro & 2001 \\
\hline Fonte: OECD (2002). & &
\end{tabular}

De acordo com uma série de trabalhos, podemos dizer que tanto o comportamento dos fundamentos macroeconômicos como a própria ação especulativa dos agentes privados têm sido importantes fatores na determinação dos distúrbios monetários em diferentes economias, variando com o tempo e lugar, o papel relativo de cada um destes fatores ${ }^{55}$.

\footnotetext{
* Mestre em Desenvolvimento Econômico pela UFPR. Endereço eletrônico: lucianofg@gmail.com

** Doutor em Economia pelo IE/UFRJ. Professor do Departamento de Economia da UFPR e Pesquisador do CNPq. Endereço eletrônico: joreiro@ufpr Site pessoal: www.joseluisoreiro.ecn.br

54 Para uma análise das características dos diferentes regimes cambiais, veja Garofalo Filho (2000).

${ }_{55}$ Para uma análise dos modelos de crises cambiais em suas três gerações, veja Gabriel (2005).
} 


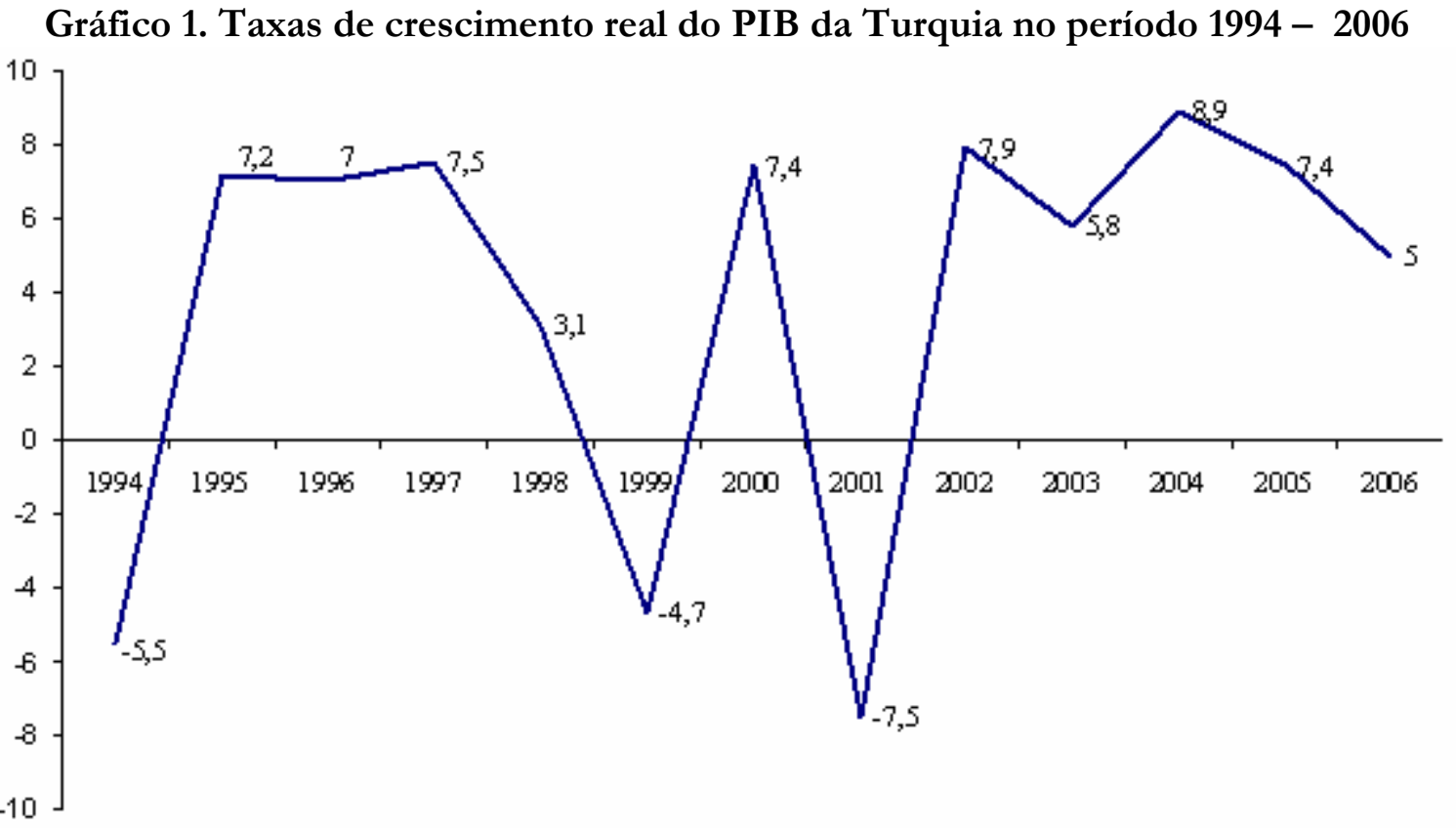

Fonte: International Monetary Fund - World Economic Outlook. 2006.

Nota: Para os anos de 2006 e os valores apresentados são estimativas do FMI.

No caso da Turquia, dúvidas em relação à viabilidade do seu sistema bancário e à sustentabilidade da dívida pública ${ }^{56}$ contribuíram sobremaneira para a manutenção de uma taxa de juros real elevada e para maxidesvalorizações da lira. Mesmo com o suporte do Fundo Monetário Internacional (FMI), a economia turca sofreu a sua pior recessão desde a Segunda Guerra Mundial, chegando a ter uma queda no PIB de 7,5\% (gráfico 1).

Em 2001, tanto o consumo agregado quanto o investimento agregado da economia turca entraram em colapso diante das perdas dos portfólios de investidores nacionais e estrangeiros, da redução abrupta do crédito (credit crunch), da incerteza política e do efeito passthough inflacionário ${ }^{57}$. Segundo relatório da OECD (2002), apesar da queda dos salários reais em 2001, o nível de desemprego subiu para seu maior patamar em duas décadas, apresentando-se como um reflexo da crise econômica do período e da profunda reestruturação do setor bancário e agrícola.

56 A dívida pública na Turquia era de $90 \%$ do PIB em 2001, sendo de curta maturidade e vinculada à taxa de câmbio.

${ }^{57}$ Para uma análise do pass-though inflacionário na Turquia, veja Leigh e Rossi (2002). 
Gráfico 2. Taxa de inflação anual na Turquia no período 1999 - 2007

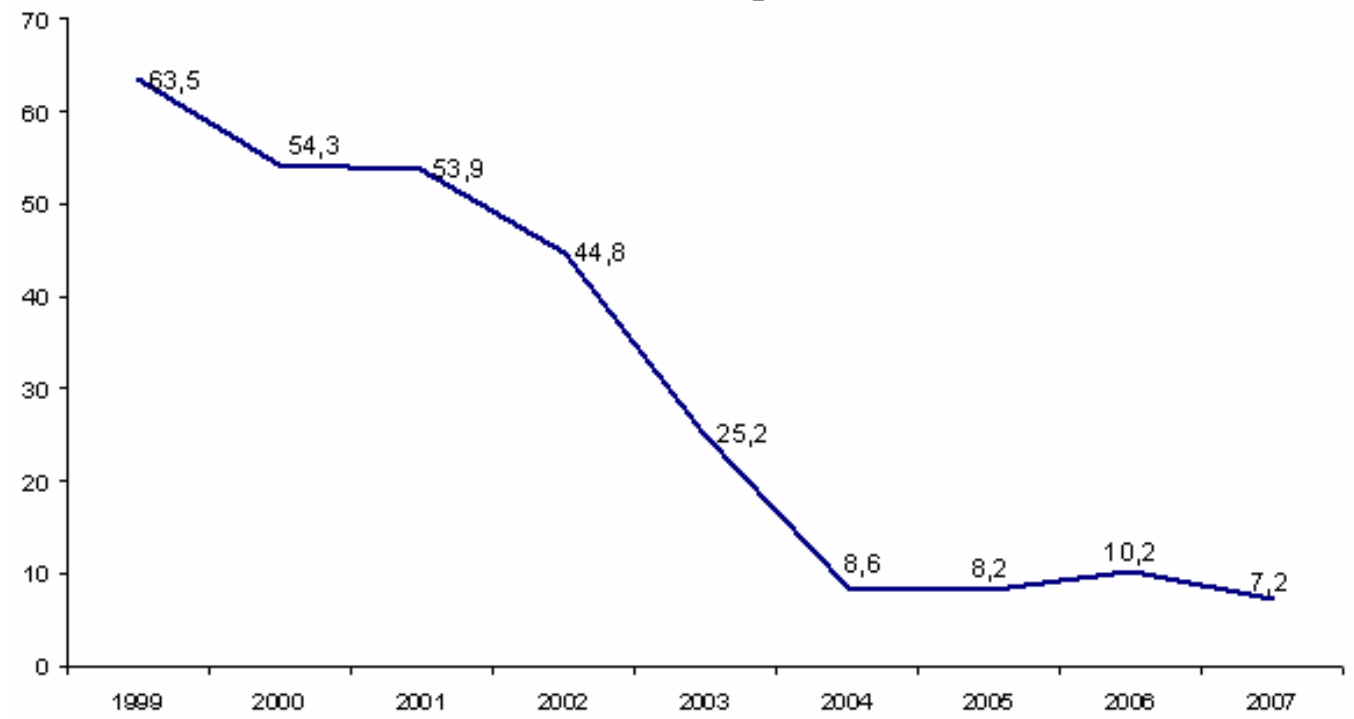

Fonte: International Monetary Fund - World Economic Outlook. 2006.

Nota: Para o ano de 2006 o valor apresentado é uma estimativa do FMI.

A respeito do credit crunch observado em 2001 na Turquia, Calvo (2001) aponta que sob a circunstância da deterioração da posição financeira de empresas domésticas devido à redução do valor de mercado de seus ativos e ao aumento do valor de suas obrigações internas e externas em moeda doméstica, pode-se observar um efeito de "evaporação de crédito", onde este se configura em uma situação na qual o volume disponível de crédito para o financiamento das atividades de rotina das empresas se reduz drasticamente. Com isto, as empresas de uma determinada economia doméstica, a exemplo da economia turca, são obrigadas a reduzir o nível de produção devido à escassez de recursos disponíveis para o financiamento de seu capital de giro ${ }^{58}$.

Depois de 1989, a Turquia vivenciou uma abertura mais intensa da sua conta de capital, sem grandes controles governamentais ou institucionais de seu setor bancário (principalmente público), o qual se tornou ao longo da década de 90 a fonte financiadora de um estoque de dívida pública crescente a taxa de juros reais elevadas. Nesse contexto, observou-se que:

58 O artigo de Calvo (2001) desenvolve um modelo simples, baseado no aspecto temporal da maturação do investimento. Esse modelo explica o que colabora para a ocorrência do colapso da produção, da crise monetária e da crise financeira. A intuição é que a reversão do fluxo de capitais esvazia a liquidez, gerando uma corrida aos bancos. A queda no crédito força uma interrupção dos investimentos, cujos projetos estavam sendo financiados anteriormente. $\mathrm{O}$ valor da liquidação desses projetos é baixo (ou zero), o que gera uma perda na produção. Nesse ponto do modelo há um déficit em conta corrente que requer uma depreciação real para retornar ao equilíbrio, por essa razão, ocorre uma desvalorização da moeda. 
'With these banks' growing involvement in government debt financing via uncovered arbitrage, they extended comparatively little credit to investment for productive activities. What lending took place was often to related parties on unprofitable terms, as large industrial conglomerates owned most of the banks, which lacked necessary skills in assessing firms' creditworthiness. To protect against high inflation, a large proportion of deposits and loans was denominated in foreign currencies and bore short maturities, but this left banks and their customers extremely vulnerable to exchange rate depreciation and interest rate increases. With the rest of the financial market remaining immature, small to medium sized companies had to rely primarily on self finance and, for the larger corporations, direct borrowing from abroad, often on the basis of bank guarantees." (OCDE; 2002, p. 3)

A canalização de recursos públicos para setores específicos de baixa rentabilidade (ou com risco elevado de bancarrota), bem como a ineficiência na alocação de crédito na economia, conteve a taxa de crescimento (nos anos de 1998 e 1999, principalmente), uma vez que o setor bancário público promoveu um efeito crowding-out dos investimentos privados e contribuiu para a crise de liquidez bancária em 1994, bem como para a crise cambial e financeira de 2001.

De uma maneira geral, Mishkin (1999) aponta duas razões para a problemática de tomada de decisões com risco excessivo no sistema bancário (em relação aos empréstimos, aplicações, dentre outros) depois de processos de liberalização financeira, como a que eclodiu no Sudeste Asiático, e mais recentemente, no caso da Turquia ${ }^{59}$. A primeira razão está relacionada à falta de expertise dos gestores do sistema bancário para o gerenciamento de risco em um contexto de novas oportunidades de empréstimos depois de processos de liberalização financeira. No caso do sudeste Asiático, Mishkin (1999) constatou que “(...) with rapid growth of lending, banking institutions could not add the necessary managerial capital (well-trained loan officers, riskassessment systems, etc.) fast enough to enable these institutions to screen and monitor these new loans appropriately (p.3)".

A segunda razão está relacionada à inadequação do sistema regulatório/supervisório a esse novo contexto de maior liberalização financeira, o qual implica em empréstimos irrecuperáveis e falências bancárias. Nesse contexto, no caso específico da Turquia:

“(...) The resulting financial and economic crisis gave rise to severe capital losses in bank and corporate sectors, mass bankruptcies and a mountain of non-performing loans. Banks faced informational

59 O trabalho de MISHKIN (1999) não apresenta nenhum modelo formal sobre a possibilidade de ocorrência de crises cambiais. Contudo, nos oferece uma síntese sobre os principais elementos desta literatura. 
uncertainties about borrowing firms while attempting to meet tighter capital adequacy requirements, and they sharply cut their credit lines, in turn aggravating the economic contraction and non-performing loan problem." (OCDE, 2002, p.3)

No episódio turco de 2001, a taxa de câmbio funcionava como uma âncora nominal para o programa de estabilização de preços. Contudo, como foi destacado, o sistema bancário estava frágil para não gerar uma crise cambial em um contexto de elevada mobilidade dos fluxos internacionais de capitais e de grande liberalização financeira com maior conversibilidade da conta de capitais.

O FMI apresentou um programa de ajuda financeira em maio de 2001, o qual foi reformulado em 2002. O programa visava reestruturar os problemas mais fundamentais da economia turca, tais como uma reforma no setor público da economia, saneamento do setor bancário e a transformação do mercado interno visando torná-lo mais atrativo para os investimentos privados.

Apesar da desconfiança dos agentes econômicos externos e internos, a Turquia, a partir de 2002, conseguiu obter taxas de crescimento acima de 7\% e uma taxa de inflação com uma tendência declinante a partir daquele ano (gráfico 2), se mostrando como uma das economias de maior crescimento da OCDE.

Segundo OCDE (2002), (2003) e (2005), as taxas de crescimento da Turquia foram puxadas pelo grande aumento de produtividade, consumo privado crescente, maior nível de investimentos e exportações ${ }^{60}$. Com o acordo com o FMI e a implementação de reformas econômicas, políticas macroeconômicas baseadas em superávits primários e uma política monetária mais restritiva contribuíram sobremaneira para conter o processo inflacionário que poderia advir com a maxidesvalorização da lira em 2001 e ensejaram, em certa medida, uma melhora do prêmio de risco turco.

A agenda macroeconômica estabelecida após a crise de 2001 baseou-se essencialmente no Programa de Convergência Nacional para a União Européia, no acordo supracitado com o FMI e no Plano de Ação Emergencial do governo da época, o qual teve continuidade nos governos seguintes. Esta agenda visava combater três armadilhas naquele país: a) baixo nível de credibilidade no programa político e macroeconômico de estabilidade de preços com altos déficits governamentais; b) falhas no setor público de uma maneira geral,

\footnotetext{
${ }^{60}$ Apesar do crescimento das exportações, as importações cresceram em um ritmo mais acelerado, fazendo com que ocorressem déficits na conta corrente da ordem de 5,2\% e 6,4\% do PIB, em 2004 e 2005, respectivamente.
} 
principalmente o bancário; e c) existência de um ambiente econômico adverso, o qual incentivava a informalidade, diminuindo a base de arrecadação do governo.

Grandes mudanças nas políticas monetária e fiscal também ocorreram. O Banco Central tornou-se independente do governo em abril de 2001, com objetivos explícitos da taxa de inflação ${ }^{61}$, sem permissão de realizar empréstimos para o Tesouro. Nesse contexto, as autoridades monetárias conseguiram melhorar a credibilidade da política monetária reduzindo paulatinamente a inflação. Estes fatos contribuíram substancialmente para a redução do riscopaís.

Do lado fiscal, a relação entre a taxa de câmbio e a dívida pública era intrincada, pois com o grande volume de dívida pública qualquer perda de confiança dos agentes econômicos internos e externos gerava aumentos na taxa de juros turca e desvalorizações cambiais, as quais impactavam nos pagamentos líquidos da dívida ${ }^{62}$.

Vale ainda dizer que, ao longo do período pós-crise de 2001, foi fundamental o papel do Banco Central fornecendo liquidez ao mercado e aumentando a oferta de moeda estrangeira para corrigir os desequilíbrios temporários da taxa de câmbio com potenciais efeitos negativos sobre a economia turca e para mudar o perfil da dívida pública, a qual possuía grande parcela atrelada à moeda estrangeira ${ }^{63}$.

Em OCDE (2002) e (2004) fica patente a ação do Banco Central da Turquia para corrigir um dos grandes problemas do câmbio flutuante com elevada mobilidade de capitais, o qual está relacionado aos ajustes excessivos (overshooting) em um curto espaço de tempo devido às mudanças abruptas das expectativas dos agentes econômicos, tendo grande potencial desestabilizador sobre a economia real, além do equacionamento paulatino dos problemas relacionados ao seu sistema bancário, bem como na mudança da composição e volume de sua dívida pública.

${ }^{61}$ A adoção do regime de metas de inflação somente se deu formalmente a partir de 2006.

${ }^{62}$ No ano de $2002,35 \%$ da dívida pública turca estava atrelada ao dólar, de forma que desvalorizações cambiais impactavam sobre o custo da dívida em termos de moeda doméstica. No acordo com o FMI, logo após a crise, o nível exigido de superávit primário foi de $6,5 \%$ do PIB.

${ }^{63} \mathrm{O}$ volume da dívida pública caiu para $70 \%$ do PIB em 2003, chegando a quase 50\% em 2004. 


\section{Referências bibliográficas}

CALVO, G. Crises de balanço de pagamentos em mercados emergentes. In: KRUGMAN, P. (org). Crises Monetárias. 1. ed. Princeton: Makron Books, 2001.

GABRIEL, L. F. Fluxos de Capitais, Fragilidade Externa e Ataques Especulativos: uma análise da experiência brasileira recente (1994-2003). Dissertação de Mestrado. Curitiba: PPGDE/UFPR, 2005.

GAROFALO FILHO, E. Câmbios no Brasil: as peripécias da moeda nacional e a política cambial, 500 anos depois 1.ed. São Paulo: Bolsa de Mercadorias e Futuros (BM\&F), 2000. p. 253.

IMF. World Economic Outlook Database. Disponível em: [http://www.img.org]. Acesso em: out. 2006.

LEIGH, D.; ROSSI, M. Exchange-Rate Pass-Through in Turkey. IMF Working Paper. WP/02/204. November, 2002.

MISHKIN, F. S. Lessons from the Asian crisis. National Bureau of Economic Research Working Papers. n.7102, April, 1999. Disponível em: [http://www.nber.org]. Acesso em: out. 2006.

OCDE. Policy Brief Economic Survey of Turkey. 2002-2004-2005. Disponível em: [http://www.oecd.org]. Acesso em: out. 2006. 
